\title{
Reconstruction of a Traumatic Cleft Earlobe Using a Combination of the Inverted V-Shaped Excision Technique and Vertical Mattress Suture Method
}

\author{
June Kyu Park, \\ Kyung Sik Kim, \\ Seung Hong Kim, \\ Jun Choi, \\ Jeong Yeol Yang \\ Department of Plastic and Reconstructive \\ Surgery, Myong-Ji Hospital, Goyang, Korea
}

\begin{abstract}
Traumatic cleft earlobes are a common problem encountered by plastic and reconstructive surgeons. Various techniques have been reported for the repair of traumatic cleft earlobes. Usually, the techniques of split earlobe repair are divided into two categories, namely straight- and broken-line repairs. Straight-line repair is simple and easy, but scar contracture frequently results in notching of the inferior border of the lobule. It can be avoided by the broken-line repair such as Z-plasty, L-plasty, or a V-shaped flap. Between April 2016 and February 2017, six patients who presented with traumatic cleft earlobe underwent surgical correction using a combination of the inverted V-shaped excision technique and vertical mattress suture method. All the patients were female and had a unilateral complete cleft earlobe. No postoperative notching of the inferior border the lobule occurred during 6-16 months of follow-up. Without the use of a broken-line repair, both the patients and the operators attained aesthetically satisfactory results. Therefore, the combination of the inverted V-shaped excision technique and vertical mattress suture method is considered useful in the treatment of traumatic cleft earlobes.
\end{abstract}

Keywords: Ear / Traumatic / Suture technique

\section{INTRODUCTION}

The current cultural and fashion trends include the increased popularity of earlobe piercing in men and multiple ear piercings in women. These have led to an increasing incidence of piercing complications such as cleft or split earlobe deformity [1]. Cleft earlobes are a common problem encountered by plastic and reconstructive surgeons. Cleft earlobes can be divided into congenital and acquired clefts. Congenital cleft earlobes are rare. However, acquired cleft earlobes are the most common type observed in female patients. Cleft, or torn and split, earlobes are usually due to sudden traction on an earring or the frequent wearing of heavy

\section{Correspondence: Kyung Sik Kim}

Department of Plastic and Reconstructive Surgery, Myong-Ji Hospital, 55 Hwasu-ro 14 Beon-gil, Deogyang-gu, Goyang 10475, Korea

E-mail:kskimps@mjh.or.kr

Received Aug 12, 2017 / Revised Nov 15, 2017 / Accepted Nov 22, 2017 earrings [1,2]. Some patients present with newly torn lobes, but most split earlobes have a chronic state. Various techniques such as the simple technique, Z-plasty, L-plasty, and V-shaped flap have been used to repair traumatic cleft earlobes [1-18]. Generally, the techniques of split earlobe repair are divided into two categories, namely straight- and broken-line repairs [3]. Straight-line repair of a traumatic earlobe is simple and easy, but scar contracture frequently results in notching of the inferior border of the lobule. The straight line can be avoided either by using Z- or L-plasty, or a $V$-shaped flap. However, despite the use of a combination of the inverted V-shaped excision technique and vertical mattress suture method without the use of a broken-line repair such as Z-plasty, L-plasty, and a V-shaped flap, we achieved the aesthetically satisfactory results. In this paper, we report six cases of traumatic cleft earlobe treated with a combination of the inverted V-shaped excision technique and vertical mattress suture method. 


\section{CASE REPORT}

From April 2016 to February 2017, six patients with traumatic cleft earlobe underwent surgical correction using a combination of the inverted V-shaped excision technique and vertical mattress suture method. Written informed consent was obtained from each patient in the study. The cause of trauma was a sudden pull on the earring. All the patients were female, with ages ranging from 10 to 32 years. They all had a unilateral complete cleft earlobe. Three patients had a left-side lesion, and the others had a right-side lesion. The clinical characteristics of the patients are summarized in Table 1.

In all the 6 cases, we used the surgical approach described below. The surgery was performed in an outpatient clinic, with the patients under local anesthesia. An inverted V-shaped design was drawn on the cleft tissue by using a marking pen (Fig. 1). The cleft was completely excised in an inverted-V fashion (Fig. 2). Both the anterior and posterior skin edges were undermined by $1 \mathrm{~mm}$. The first key suture is used to align the margins at the inferior border of the earlobe. The skin edges were everted and approximated with the vertical mattress sutures and interrupted simple sutures (Fig. 3). Everting the inferior earlobe with a vertical mattress suture decreased the notching defect observed with healing contraction [4].

Stitches were removed 7 days after the operation. Tapes were applied for 2 weeks after the removal of the stitches, followed by silicone ointment application for the scar for 6 months. No postoperative notching of the inferior border the lobule was observed during 6-16 months of follow-up (Figs. 4, 5).

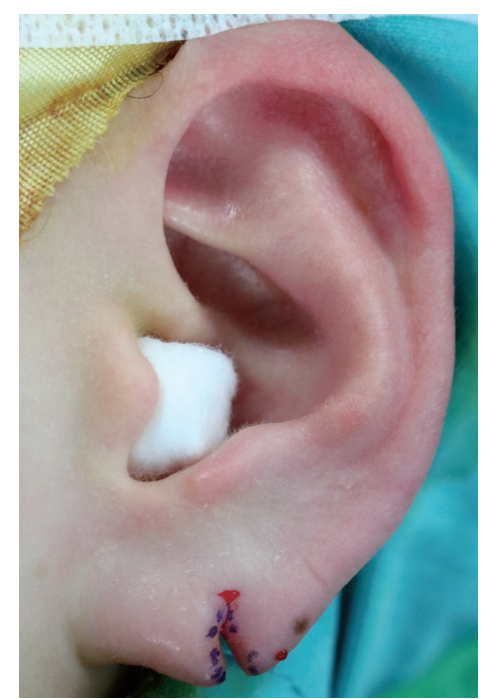

Fig. 1. Dotted lines indicate the areas of excision of the cleft tissue.

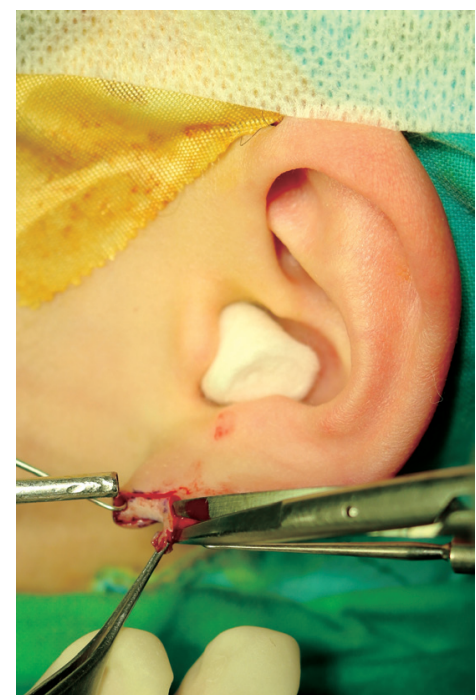

Fig. 2. Cleft tissue excised in an inverted-V fashion.

Table 1. Summary of the patients' characteristics

\begin{tabular}{|c|c|c|c|c|c|c|c|}
\hline Case no. & Age $(y) / \operatorname{Sex}$ & $\begin{array}{l}\text { Cause of } \\
\text { injury }\end{array}$ & Type of traumatic cleft earlobe & $\begin{array}{l}\text { Side of cleft } \\
\text { earlobe }\end{array}$ & Duration (wk) & $\begin{array}{l}\text { Follow-up } \\
\text { (mo) }\end{array}$ & Complication \\
\hline 1 & 28/Female & Earring & Complete/Unilateral & Left & 2 & 6 & None \\
\hline 2 & 24/Female & Earring & Complete/Unilateral & Left & 2 & 16 & None \\
\hline 3 & 10/Female & Earring & Complete/Unilateral & Left & 14 & 7 & None \\
\hline 4 & 25/Female & Earring & Complete/Unilateral & Right & 20 & 15 & None \\
\hline 5 & 15/Female & Earring & Complete/Unilateral & Right & 8 & 7 & None \\
\hline 6 & 32/Female & Earring & Complete/Unilateral & Right & 1 & 6 & None \\
\hline
\end{tabular}



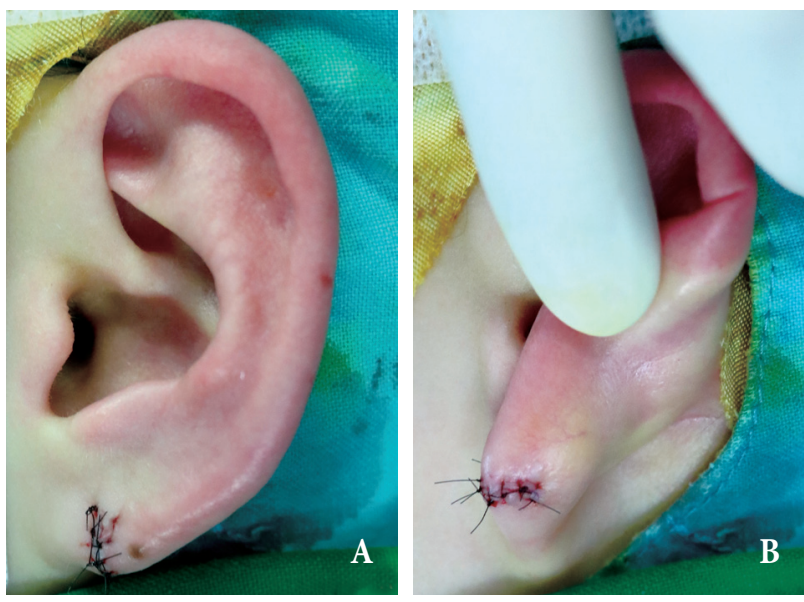

Fig. 3. Final skin sutures on the earlobe. (A) The front of the earlobe. (B) The back of the earlobe.
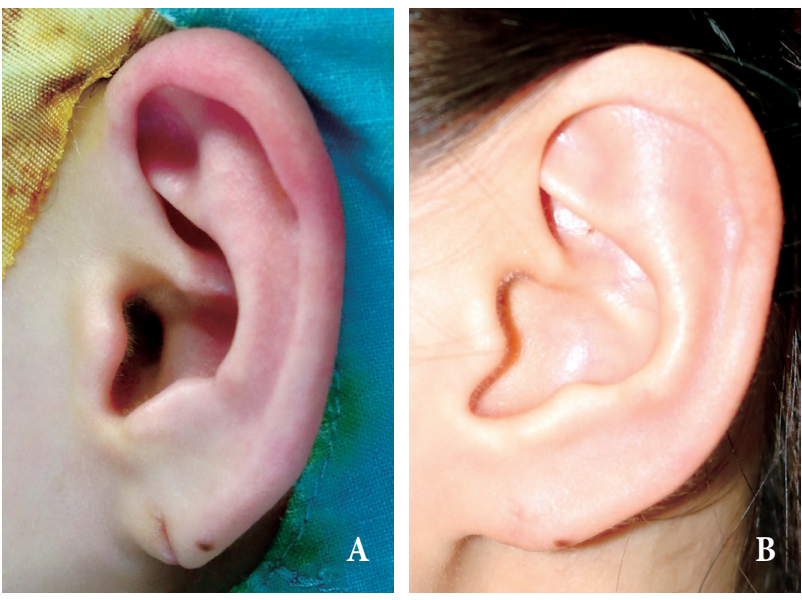

Fig. 4. Case 1. A 28-year-old woman with a complete cleft earlobe on the left side. (A) Preoperative photograph. (B) Postoperative 6-month photograph showing good cosmetic result without notching of the inferior border of the lobule.

In case 1, a 28-year-old woman with a left cleft earlobe due to a sudden pull of her earring 2 weeks before visited our outpatient plastic surgery department (Fig. 4A). She did not wear her earrings after the accident and wanted her left earlobe to be completely healed. We reconstructed the traumatic cleft earlobe by using a combination inverted V-shaped excision technique and the vertical mattress suture method. After the operation, she was satisfied with the results. During the 6-month follow-up, no notching of the inferior border of the lobule was observed (Fig. 4B).

In case 2, a 24-year-old woman presented with a left cleft ear-
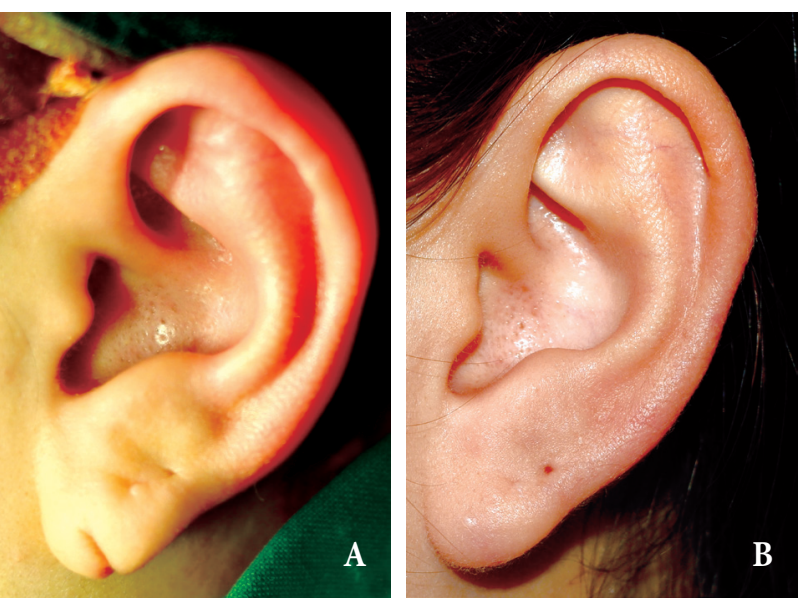

Fig. 5. Case 2. A 24-year-old woman with a complete cleft earlobe on the left side. (A) Preoperative photograph. (B) Postoperative 16-month photograph showing good cosmetic result without notching of the inferior border of the lobule.

lobe due to a sudden traction of her earring 2 weeks prior (Fig. 5A). She hoped her left earlobe to be completely healed after surgery. We repaired the traumatic cleft earlobe using a combination of the inverted $\mathrm{V}$-shaped excision technique and vertical mattress suture method. Her earlobe healed without operation-related wound problems. Eventually, no notching of the inferior border of the lobule was observed during the 16-month follow-up period (Fig. 5B).

\section{DISCUSSION}

Cleft earlobes can be divided into two categories: congenital and acquired (traumatic) [6]. The differences between congenital cleft earlobes and traumatic cleft earlobes are as follows [19]. (1) Most congenital cleft earlobes represent tissue deficiency, whereas some traumatic cleft earlobes represent enlarged lobules. (2) Most congenital cleft earlobes have curved cleft margins, whereas most traumatic cleft earlobes have linear cleft margins. (3) Congenital cleft earlobes often have two different sized components on either side of the cleft, whereas most traumatic cleft earlobes have two equal volume components on each side of the cleft.

Traumatic cleft earlobes can be classified as having a complete, incomplete, unilateral, or bilateral cleft [1,2]. Most complete clefts are unilateral, resulting from acute trauma such as sudden trac- 
tion on an earring. On the contrary, incomplete cleft tends to be bilateral and occurs as a result of frequent wearing of heavy and pendulous earrings for several decades.

Many techniques have been described for the surgical treatment of traumatic earlobes [1-18]. In 1954, McLAREN [5] first reported a simple linear closure after excision of scar tissue of a complete cleft earlobe. In 1961, Boo-Chai [6] described excision of the cleft and a linear closure around a matchstick to preserve the opening for an earring. In 1973, Pardue [7] improved upon Boochai's technique by using a small transpositional flap to recreate a hole for an earring at the time of the repair. In 1975, Hamilton and LaRossa [8] expanded on Pardue's technique with the addition of a Z-plasty on the inferior rim of the earlobe to avoid notching. In the same year, Buchan [9] introduced a technique to preserve the earring hole that used a superiorly based flap from noncleft skin and designed Z-plasty at the inferior margin.

In 1978, Argamaso [10] published a triangular lap joint flap technique with preservation of the earring hole. In 1982, Harahap [11] introduced another variation of Z-plasty on the anterior and posterior sides of the lobule without reconstruction of the earring hole. In 1984, Kalimuthu et al. [12] proposed a V-shaped flap to reduce the risk of notching of the inferior rim. This technique does not preserve the earring hole. In 1985, Fatah [3] reported a Lplasty technique with or without reconstruction of the earring hole. One year later, Elsahy [13] reported preservation of the earring hole during cleft reconstruction, based on the concept of small superior based flap and linear closure. In 1987, Zoltie [14] described a rectangular lap joint flap technique with preservation of the earring hole. In 1993, Apesos and Kane [15] published an inverted V-shaped excision technique and a straight-line closure without preservation of the earring hole. Since then, several techniques have been reported, such as tong-in-groove technique and double triangular flap $[16,17]$.

Regardless of whether the piercing site is preserved, the techniques of traumatic earlobe reconstruction are divided into two categories, namely straight- and broken-line repairs [3]. Straightline repair of a traumatic earlobe is simple, easy, and fast. However, scar contracture frequently results in notching of the inferior border of the lobule and a groove along the suture line. However, the straight line can be avoided by using a small local flap such as Zplasty, L-plasty, or a V-shaped flap [2,3]. These methods reduce the risk of notching of the inferior rim due to scar contracture. However, making a tiny incision and suturing small flaps need not only technical precision but also more operation time and surgical effort. Besides, small flaps on the cleft margin always have the risk of flap necrosis caused by ischemic condition [16].

Generally, inferior lobe notching is a complication of the simple technique, caused by inaccurate approximation of the skin edges or scar contracture [18]. Thus, we made a delicate key suture at the inferior border of the earlobe to reduce notching of the inferior lobe border caused by malalignment and eversion of the skin edge through the vertical mattress to remove notching of the inferior lobe in the simple technique and used postoperative silicone ointment. As a result, without the use of a broken-line repair such as Z-plasty, L-plasty, or a V-shaped flap, we obtained aesthetically satisfactory results. Therefore, the combination the inverted Vshaped excision technique and vertical mattress suture method is considered effective in the treatment of traumatic cleft earlobes.

\section{CONFLICT OF INTEREST}

No potential conflict of interest relevant to this article was reported.

\section{PATIENT CONSENT}

The patient provided written informed consent for the publication and the use of their images.

\section{REFERENCES}

1. Blanco-Davila F, Vasconez HC. The cleft earlobe: a review of methods of treatment. Ann Plast Surg 1994;33:677-80.

2. Watson D. Repair of the torn earlobe. Facial Plast Surg 2004;20:39-45.

3. Fatah MF. L-plasty technique in the repair of split ear lobe. Br J Plast Surg 1985;38:410-4.

4. Vujevich J, Goldberg LH, Obagi S. Repair of partial and complete earlobe clefts: a review of 21 methods. J Drugs Dermatol 2007;6:695-9.

5. McLAREN LR. Cleft ear lobes: a hazard of wearing ear-rings. Br J Plast Surg 1954;7:162-5. 
6. Boo-Chai K. The cleft ear lobe. Plast Reconstr Surg Transplant Bull 1961;28:681-8.

7. Pardue AM. Repair of torn earlobe with preservation of the perforation for an earring. Plast Reconstr Surg 1973;51:472-3.

8. Hamilton R, LaRossa D. Method for repair of cleft earlobes. Plast Reconstr Surg 1975;55:99-101.

9. Buchan NG. The cleft ear lobe: a method of repair with preservation of the earring canal. Br J Plast Surg 1975;28:296-8.

10. Argamaso RV. The lap-joint principle in the repair of the cleft earlobe. Br J Plast Surg 1978;31:337-8.

11. Harahap M. Repair of split earlobes: a review and a new technique. J Dermatol Surg Oncol 1982;8:187-91.

12. Kalimuthu R, Larson BJ, Lewis N. Earlobe repair: a new technique Plast Reconstr Surg 1984;74:299-300.

13. Elsahy NI. Reconstruction of the cleft earlobe with preservation of the perforation for an earring. Plast Reconstr Surg 1986;77:322-4

14. Zoltie N. Split earlobes: a method of repair preserving the hole. Plast Reconstr Surg 1987;80:619-21.

15. Apesos J, Kane M. Treatment of traumatic earlobe clefts. Aesthetic Plast Surg 1993;17:253-5.

16. Oh DY, Kim SW, Ahn ST, Rhie JW. Correction of earlobe cleft with tongue-in-groove technique. J Craniofac Surg 2011;22:1785-7.

17. Kang S, Moon SJ, Suh H. Traumatic cleft earlobe repair: using a double triangular flap for differently sized components on either side of the cleft. Aesthetic Plast Surg 2013;37:1163-6.

18. Niamtu J 3rd. Surgical repair of the cleft earlobe. J Oral Maxillofac Surg 1997;55:886-90.

19. Fujiwara T, Matsuo K, Taki K, Noguchi M, Kiyono M. Triangular flap repair of the congenital earlobe cleft. Ann Plast Surg 1995;34:402-5. 